\title{
DIVULGANDO A FENOMENOLOGIA ONTOLÓGICA - HERMENÊUTICA DE MARTIN HEIDEGGER
}

Regina Lúcia M. Lopes ${ }^{1}$, Inês Emília de Oliveira², Marta Mª Coelho Damasleno

RESUMO: A referente revisão de Literatura visa a divulgar a proposta de Fenomenologia, bem como registrar o pensamento filosófico de martin Heidegger, nome de destaque na produção científica em Enfermagem.

DESCRITORES: Filosofia em Enfermagem.

\section{DIVULGING THE ONTHOLOGICAL HERMENEUTICS PHENOMENOLOGY OF MARTIN HEIDDEGER}

ABSTRACT: The literary review aims to divulge Phenomenology proposal as well to register Martin Heidegger's philosophical thinking, illustrious name in nursing academic production.

DESCRIPTORS: Phylosophy; Nursing.

\footnotetext{
${ }^{1}$ Professora da Universidade Federal da Bahia-UFSC. Doutora em Enfermagem.

${ }^{2}$ Professora da UFBA. Doutora em Enfermagem.

${ }^{3}$ Professora da Escola de Enfermagem Anna Neri -Uiversidade Federal do Rio de Janeiro. Doutora em Enfermagem.
} 


\section{A PROPOSTA DA FENOMENOLOGIA E A ENFERMAGEM}

A filosofia fenomenológica, defenddida como ciência de rigor na Alemanha, com os estudos de Edmund Husserl, nasceu como uma reação ao empirismo positivista.

Ao abordar o cenário em que a Fenomenologia desponta, Dichtchekenian et al. (1988-8) afirmam que esta surge como meio de tornar acessível ao ser humano o encontro com ele mesmo naquilo que mais o caracteriza recuperar a sua presença no mundo.

Vários autores, dentre eles bicudo (1983:10) \& Donzelli (1988:44) consideram-na um método apropriado aos estudos dos fenômenos humanos e sociais. Afirmam, ainda, que essa abordagem não configura substituição ou oposição ao pensamento objetivista e positivista das ciências exatas. Como uma proposta de compreensão do humano, é uma possibilidade de conhecimento, de saber paralelo ao científico.

Bicudo (1983:11) declara que esta corrente filosófica, como uma forma radical de pensar, não se destina à tarefa de explicação dos fatos. Seu compromisso é o de ir além do já demonstrado, buscando o fundante presente em todo comportamento humano.

Assim sendo, a Fenomenologia não procura as condições sobre as quais o juízo é verdade e, sim, o sentido que funda o comportamento do indivíduo quando ele ama, sente felicidade, adoece, vive..., e que é expresso através do discurso - mundo da linguagem, da totalidade das palavras, dos gestos, do silêncio, do tom do voz, da expressão fisionômica e do discurso escrito. (Lopes et al., 1995:50)

Questões significativas à existência humana, como o amor, a angústia, a liberdade, a desesperança, o medo e o próprio existir, dão-se no homem e merecem um olhar de natureza compreensiva. Não se esgotando o homem na entidade encarnada em que ele se dá, questões dessa natureza não podem ser tratadas como fatos.

A razão de ser da Fenomenologia é segundo Dichtchekenian et al. (1988:10) a insistência no convívio, a partir de um espaço que se abre e nos solicita no compromisso pessoal.

A Fenomenologia apresentou-se como uma proposta de compreensão do humano em seu cotidiano vivencial, por meio da descrição do fenômeno que a experiência dos fatos nos oferece para chegar a sua essência.

A década de 80 marcou o início da produção cinetífica de Enfermagem com a abordagem fenomenológica. Nos anos 90, houve um interesse crescente pela utilização da Fenomenologia no desenvolvimento de estudos realizados por enfermeiros docentes e assistenciais, valorizando-se, assim, as experiências vivenciadas pelos humanos a quem os cuidados de Enfermagem são dirigidos. (Damasceno et al., 1995)

Neste entendimento, os enfermeiros, apropriando- se dos referenciais filosóficos de Martin Heidegger, Maurice Merleau Ponty e Alferd Schutz, têm dirigido suas preocupações para a compreensão de muitas situações de saúde e doenças experienciadas pela clientela. Assim, no aprofundamento de temáticas que buscam a compreensão do humano como projeto, como possibilidade pura, como poder-ser, a qual, assim, segundo seu modo de ser, vivencia situções existenciais, a Fenomenologia Ontológico Hermenêutica de Martin Heidegger, apresentada em Ser e Tempo, tem-se mostrado como o caminho mais utilizado pelos enfermeiros no desenvolvimento de seus estudos.

\section{MARTIN HEIDEGGER: O HOMEM E O FILÓSOFO DO SER}

Martin Heidegger (1889 - 1976), alemão de formação teológica e filosófica, é um dos pensadores que mais agitou a filosofia contemporânea. Nome ligado ao Existencialismo, apresentava reservas quanto a aceitar sua suposta filiação à essa direção da Fenomenologia (PENHA, 1990:25).

Martins (1983:33), ao analisar o cenário contemporâneo, considera-o o mais independente, subsistente, firme e sólido pensador da condição do ser humano. Em análise da originalidade e profundidade da obra heiddegeriana, Miranda (1988:307) associa o pensador a filósofos de renome indiscutível, como Platão e Hegel.

Segundo Chacon (1979:16), Heidegger teve também sua imagem fortemente associada ao nazismo quando, ao ser indicado como reitor da Universidade de Freiburg, seu discurso de posse, intitulado Auto - afirmação da universidade Alemã, fez época, por convocar discentes aos serviços da defesa militar. Tendo-se filiado ao movimento nacional-socialista em ascensão, aponta-o como a alternativa entre o comunismo e o capitalismo. (Penha, 1990:36)

No entanto, miranda (1976:269) afirma que ele proibiu, na Universidade, a propaganda anti - semita dos estudantes nazistas, assim como impediu a queima de livros de autores contrários ao regime. Chacon (1979:16) complementa que ele defendeu a manutenção, na instituição, de professores judeus ou adversários ao movimento.

Tendo pensado, inicialmente, em alguma "verdade interna e grandeza do movimento", permaneceu no reitorado por 10 meses, renunciando ao cargo antes que os plenos poderes fossem dados a Hitler e que esse estabelecesse as leis racistas de Nuremberg (CHACON, 1979: 17).

Tendo-se desligado do movimento, passou a fazer críticas ao regime durante seus cursos, sendo vigiados na suas atividades, até que, então, foi afastado do exercício da cátedra. Convocado após o término da II Guerra para trabalhos braçais, ingressou, posteriormente, como um dos mais velhos soldados - rasos da Alemanha (CHACON, 1979:17).

O mesmo autor complementa que Heidegger foi feito

Cogitare Enferm., Curitiba, v. 1 n. 2, p. 53-56 - jul./dez. 1996 
prisioneiro de guerra e libertado após um expressivo abaixo - assinado de intelectuais mundiais de várias tendências políticas.

O filósofo manteve silêncio sobre sua possível adesão ao nazismo, até que, segundo Penha (1990:36), em 1966, concedeu uma entrevista a uma revista alemã, prestando declarações sob a promessa destas só serem divulgadas após a sua morte, acordo que foi cumprido pela editora. Esses seus únicos esclarecimentos, além de testemunhos escritos e públicos de ex-alunos e colegas seus, dessa época, constituem a fonte em que os estudiosos se baseiam para aclarar esse lado obscuro da vida desse pensador.

$\mathrm{Na}$ publicação de Meu caminho para a Fenomenologia, Heidegger reafirma que foi conduzido à questão central de sua investigação, iluminado pela Fenomenologia. Seu primeiro contacto com os escritos de Edmund Husserl, Investigações Lógicas, bem como com a dissertação de Franz Brentano, que versava sobre a concepção aristotélica do múltiplo significado do ente, ocorreram na Faculdade de Teologia. Após a formação filosófica e a sua opção por dedicar-se à docência, veio a oportunidade de desenvolver suas atividades junto a Husserl, de quem tinha sido aluno. Assim, diz Heidegger (1979:299) aprendeu o ver fenomenológico, nele se exercitou e experimentou uma nova compreensão de Aristóteles.

Com estudos aprofundados e analisando o princípio da Fenomenologia divulgado pela máxima Husserliana, questiona-se ser "a coisa mesma" a consciência e sua objetividade, ou o ser do ente em seu desvelamento e ocultação (HEIDEGGER, 1979:300). Aqui se bifurcam Heidegger e Husserl, a quem, em feiburg, substitui na cátedra de filosofia, por indicação do mestre.

Ele afirma que a Fenomenologia é possibilidade de pensamento que, periodicamente, se transforma e somente assim permanece, e de corresponder ao apelo do que deve ser pensado (HEIDEGGER, 1979:301). A partir desta compreensão e permanecendo fiel ao método idealizado por Husserl, a Fenomenologia constitui o caminho para o sentido do ser - objeto da investigação ontológica Heideggeriana.

Segundo Stein (1979:6), toda a obra de Heidegger durante o período de 1914 a 1970, é constituída de livros, ensaios e conferências que representam um acervo significativo, sendo que muito desse riquíssimo material ainda está por ser traduzido. Desse acervo constam as seguintes produções: (1914) A teoria do juízo no psicologicismo - Contribuição Crítico positiva à Lógica; (1916) Doutrina das Categorias e da Significação em Duns Escoto; (1927) Ser e Tempo; (1928) A Determinação do Ser do Ente segundo Leibniz; (1929) Que é a Metafísica; Kant e o problema da Metafísica; Sobre a essência do Fundamento; (1930) Sobre a Essência da verdade; (1936) Hölderlin e a essência da Poesia; (1934)Sobre a Essência da verdade; (1947) A doutrina Platônica da verdade; (1949)
Sobre o Humanismo; (1953) 1 INTRODUÇÃO à Metafísica; (1954) Que significa pensar, sobre a essência do pensar; (1955) Que é isto - a filosofia?; (1956) Sobre a questão do ser; (1957) Identidade e diferença; O princípio do Fundamento; Sendas Perdidas; (1958) Hegel e os gregos; (1959)Serenidade; Pelos Caminhos da Linguagem; (1961) Nietzsche; (1962) A Questão da coisa; A tese de Kant sobre o ser; (1963) Tempo e Ser, Meu caminho para a Fenomenologia; (1966) O fim da Filosofia e a tarefa do Pensamento; (1969) A questão do pensar, e (1970) Heráclito.

Na opinião de Botelho (1976:364), os três grandes momentos de reflexão Heideggeriana são os registrados em Sobre a essência da verdade; Nietzsche; e Ser e Tempo sua mais imponente obra.

A questão da ontologia perpassa toda a criação de Heidegger e reflete uma crítica ao mundo contemporâneo, à civilização tecnicista e à perda do sentido da Filosofia. Segundo Chacon (1979: 11-14), em nenhum outro pensador do século XX, surge, de modo tão claro a crise do Ocidente, quanto em Heidegger, a Europa, centro da Crise da Cultura, estaria perdendo sua identidade diante da influência da União da União Soviética e dos Estados Unidos da América, potências sem tradição e mais predispostas ao fazer que ao ser.

Assim, o marco fundamental do pensar de Heidegger é a tentativa de compreensão e admiração do ser, este que esta-aí porque o homem assim está como presença. $\mathrm{O}$ humano que esta-aí, sempre no exercício da meditação e da indagação em direção ao ser. (PEREIRA, 1993:401)

Heidegger teve como mérito repor, no centro da reflexão filosófica, a temática tradicional: o sentido do ser. Impulsionado por essa única questão, a proposição originária de analisar o ente na busca de caminhos que levem ao ser, esteve presente em seus escritos até 1930. A partir daí, sua produção revela uma preocupação de analisar o ser em si-mesmo e sua auto - revelação, o que, para muitos, caracteriza a sua segunda fase do pensamento filosófico (Reale \& Antiseri 1991:582). Essa fase no projeto filosófico, significa uma mudança de enfoque nos temas por ele já explorados.

Nesse sentido, Palmer (1989:145-146) observa que, embora, em suas últimas obras, o filósofo se apresente mais poético, obscuro e profético, sua busca essencial - a revelação do ser - não se alterou, apenas se revelou mais plenamente, oportunizando, assim, aprofundar aspectos de sua obra - prima.

Em toda a vasta exensão da obra heiddegeriana, há uma preocupação em explorar as raízes da linguagem, o que garante á sua invistigação fílosófica uma riqueza semântica. Dando designação diferenciada a certos termos utilizados pela filosofia clássica, Heidegger reveste-os de um significado especial, valorizando sobremaneira as raízes das palavras gregas e alemãs.

Chamando atenção para a noção etimológica, utilizase da hifenação, não no sentido comum de efeito de ligação 
entre elementos de palavras compostas, mas como artifício ortográfico, através de cadeias de hífens que declaram o retorno às origens da linguagem. Ao hifenizar, está chamando a atenção para o fundante, possibilitando que o sentido da palavra se revele.

Segundo Gilles (1975:249), Heidegger tenta, pela manipulação das etimologias, através da redução do uso corrente de palavras, faze-las revelar o sentido implícito e, dessa forma, retomar a linguagem do homem em sua linguagem significativa. Heidegger prima, assim, por "polir" as palavras até que seu esplendor originário volte a brilhar. (Palmer, 1986: 152)

A estreita ligação de seu pensar às pesquisas lingüísticas, proclama ser a linguagem não uma construção humana de sinais convencionais, mas a casa do ser e o homem habita a sua beira. (Logos, 1989:1059)

$\mathrm{Na}$ análise desse artifício, Silva (1951:279-280) declara que Heidegger procura mostrar, ao longo de seus ensaios, como a clareza matemática e a objetividade influenciaram o pensamento ocidental. Na rtendência de instituir uma linguagem que veiculasse essa objetividade universal, afastamo-nos das autênticas intenções do discurso humano.

A criação de cada palavra expõe a constituição de um mundo. A linguagem é, assim, um chamamento ao ser, ou seja, ela concreta o sentido que funda aquele estar no mundo da qual a palavra faz parte no discurso.

\section{CONSIDERAÇÕES SOBRE A FENOMENOLOGIA}

A Fenomenologia vem somar-se ao saber dos fatos, e busca o que está velado na facticidade. Assim, a partir dos fatos, mas deles não derivando, busca o sentido, ou seja o que está na vivência.

Martin Heidegger, pensador de suporte de muitos estudos relaizados por enfermeiros, entende o homem como aquele ente cuja essência é ex-sistir, é acontecer. Ex-sistir é estar fora da realidade e em direção à possibilidade.

As situações que caracterizam o cotiudiano assistencial, tem-nos impulsionado, enquanto enfermeiros, a direcionar a nossa atenção para a compreensão do exsistir do humano a quem nos é confiado o cuidado. O olhar compreensivo que essa abordagem possibilita, não referese a um simples conhecimento objetivo através da capacidade de sentir o que o outrem experimenta. Diz respeito ao poder de captar as possibilidades que cada um é, no contexto de mundo em que cada é, no contexto de mundo em que cada humano ex-siste e compartilha experiências.

\section{REFERÊNCIAS}

1. BICUDO, Maria Aparecida Viggiani. Prefácio. In: Estudos sobre existencialismo, fenomenologia e educação. Joel Martins e Maria Aparecida Viggiani Bicudo. São Paulo:
Moraes, 1983. p.7-16.

2. BOTELHO, Afonso. Martin Heidegger. Revista Brasileira de Filosofia. Rio de Janeiro, v.30, n. 113, p. 364-366, jul./ set. 1976.

3. CHACON, Vamireh. Heidegger e atragédia do Ocidente. Revista Brasileira de Filosofia. Rio de Janeiro, v.30, n.113, p. 11-26, jan. /mar. 1979.

4. DAMASCENO, Marta $\mathrm{M}^{\mathrm{a}}$ Coelho et al. Fenomenologia e a produção científica de Enfermagem. 1995. (apostila)

5. DICHTCHEKENIAN, $\mathrm{M}^{\mathrm{a}}$ Fernanda S.F.B. 1 INTRODUÇÃO. In: ___ (Org.). Vida e morte: ensaios fenomenológicos. São Paulo: Companhia Ilimitada, 1988, p. 7-10.

6. DONZELLI, Telma Aparecida. Método Fenomenológico e Ciências Humanas. In: Teorização do Serviço Social. Doc. Alto da Boa Vista. Rio de Janeiro: Agir, 1988, p: 44 - 49.

7. GILES, Thomas Ramson. Martin Heidegger. In: História do Existencialismo e da Fenomenologia. São Paulo, EPU/ EDUSP, 1975. v.I, p. 187-299.

8. HEIDEGGER, Martin. Meu caminho para a fenomenologia. In: Conferências e escritos filosóficos: Martin Heidegger. São Paulo: Abril Cultural, 1979. p. 294 -301. (Coleção os Pensadores)

9. LOGOS. Enciclopédia Luso-Brasileira de Filosofia. Lisboa, Editorial Verbo, 1989.

10. LOPES, Regina Lúcia Mendonça et al. A Fenomenologia e a Pesquisa em Enfermagem. Revista Enfermagem UERJ. Rio de Janeiro, v. 3, n.1, p. 49-52, maio de 1995.

11. MARTINS, Joel. A ontologia de Heidegger. In; Martins, J, Bicudo, M.A.V. Estudos sobre Existencialismo, Fenomenologia e Educação. Joel Martin e $\mathrm{M}^{\mathrm{a}}$ Aparecida Viggiani Bicudo. São Paulo, Moraes, 1983. p. 33-44.

12. MIRANDA, $\mathrm{M}^{\mathrm{a}}$ do Carmo Tavares de. O livro "Heidegger e o Nazismo". Revista Brasileira de Filosofia. Rio de Janeiro, v. 37, n. 152, p.303-307, out. /dez. 1988.

$13 . \quad$ Martin Heidegger: o filósofo do ser. Revista brasileira de Filosofia. Rio de janeiro, v. 17, n. 103, p. $267-$ 274, jul./set. 1976.

14. PALMER, Richard E. o último contributo de Heidegger para a teoria hermenêutica. In: Hermenêutica. Lisboa, edições 70, 1986. p. 145-165.

15. PENHA, João da. As correntes existencialistas: Heidegger. In: O que é existencialismo. 11 ed. São paulo, brasiliensae, 1990. p. 25-37. (Coleção Primeiros Passos; v. 61).

16. PEREIRA, Otaviano. O problema da verdade e liberdade em Heidegger. Reflexão. Campinas, v.18, n. 55/56, p. 393-417, jan./ ago. 1993.

17. REALE, Giovanni, ANTISERI, Dario. Martin Heidegger: da fenomenologia ao existencialismo. In: História da Filosofia. São Paulo: Paulinas, 1991, v.3, p.581-592.

18. SILVA, Vicente Ferreira da. A última fase do pensamento de Heidegger. Revista Brasileira de Filosofia. Rio de Janeiro, v.I, n.3, p. 278-289, jul./set., 1951.

19. STEIN, Ernildo. Prefácio. In: Coferências e escritos filosóficos. Martin Heidegger. São Paulo: abril Cultural, 1979. p.6. (Coleção os Pensadores). 